\title{
Proposta de atuação do psicólogo hospitalar em maternidade e UTI neonatal baseada em uma experiência de estágio
}

\author{
Motion performance psychologist's hospital in maternity and newborn ICU based on \\ a stage experience \\ Propuesta para el papel del psicólogo de la salud en la maternidad y UCI neonatal \\ basado en una experiencia stage
}

\author{
Alessandra da Rocha Arrais \\ Universidade Católica de Brasília \\ Mariana Alves Mourão
}

\begin{abstract}
Resumo
Atualmente, já é possível encontrar muitos escritos a respeito da atuação de psicólogos em hospitais, principalmente em relação a seu papel, que geralmente está associado a ajudar pacientes e acompanhantes a lidarem com suas doenças e hospitalização. Porém, encontra-se pouco na literatura a respeito da atuação do psicólogo hospitalar aplicada à obstetrícia. Há muitos livros e artigos que tratam a respeito da relação mãe/bebê, dos sentimentos e emoções de casais que passam pela gestação, parto e pós-parto. Porém, não há uma sistematização de como podemos usar este conhecimento na prática dos psicólogos nas maternidades e UTIs Neonatais. Pretendemos com este trabalho compartilhar com os psicólogos hospitalares nossa experiência em uma maternidade e na UTI Neonatal de um hospital privado, sugerindo uma proposta que construímos para estruturar e facilitar a atuação de psicólogos nesta área. O mesmo é resultado de um estágio acadêmico de pós- graduação na Universidade Católica de Brasília-UCB, realizado em uma maternidade particular de Brasília.
\end{abstract}

Palavras-chave: Psicólogo hospitalar; Maternidade; UTI Neonatal.

\begin{abstract}
Currently, it is possible to find many writings about the role of psychologists in hospitals, especially in relation to their role, which is usually associated with help patients and caregivers cope with their illness and hospitalization. However, there is little in the literature about the performance of hospital psychologists applied to obstetrics. There are many books and articles dealing with the relationship mother / baby, the feelings and emotions of couples who go through pregnancy, childbirth and postpartum. However, there is a systematization of how we can use this knowledge in practice of psychologists in hospitals and NICUs. We intend to share this work with health psychologists our experience in maternity and neonatal ICU of a private hospital, suggesting that a proposal to build structure and facilitate the activities of psychologists in this area. The same is the result of an academic internship graduate from the Catholic University of Brasilia-UCB, held in a private maternity hospital in Brasilia.

Key-words: Hospital psychologist; Maternity; NICU.
\end{abstract}

\section{Resumen}

En la actualidad, es posible encontrar muchos escritos sobre el papel de los psicólogos en los hospitales, especialmente en relación con su papel, que generalmente se asocia con ayudar a los pacientes y cuidadores hacer frente a su enfermedad y hospitalización. Sin embargo, hay muy poco en la literatura sobre el desempeño de los psicólogos del hospital se aplican a la obstetricia. Hay muchos libros y artículos que tratan de la relación madre / hijo, los sentimientos y las emociones de las parejas que pasan por el embarazo, el parto y el posparto. Sin embargo, existe una sistematización de cómo podemos utilizar este conocimiento en la práctica de los psicólogos en los hospitales y las UCIN. Tenemos la intención de compartir este trabajo con psicólogos de la salud de nuestra experiencia en la maternidad y la unidad de cuidados intensivos neonatal de un hospital privado, lo que sugiere que la propuesta de construir la estructura y facilitar las actividades de los psicólogos en este ámbito. El mismo es el resultado de una pasantía de postgrado académico de la Universidad Católica de Brasilia-UCB, que tuvo lugar en una maternidad privada en Brasilia.

Palabras-clave: Psicóloga del hospital; Maternidad; UCIN.

\section{INTRODUÇ̃̃O}

Este trabalho é resultado da experiência de estágio acadêmico de pós- graduação em Psicologia Hospitalar

Endereço 1 : Campus Avançado Asa Norte - SGAN 916 Módulo B Avenida W5 - CEP: 70790-160 - Brasília/DF.

Endereço 2: SHA conjunto 6 Chácara $18 \mathrm{~F}$ lote $5 \mathrm{~A}$ - Arniqueiras, Brasília-DF. CEP:71996-165. da Universidade Católica de Brasília, realizado na maternidade e UTI Neonatal (UTIN) de um hospital privado de Brasília, no ano de 2011. Pretende-se expor a rotina de assistência psicológica construída nestes setores, as quais prevêem uma prática humanizada de atendimento. Para tanto, abordaremos os desafios de um serviço de obstetrícia, assim como questões que permeiam a internação de gestantes, parturientes, puérperas e neonatos. A partir de um enfoque da 
psicologia hospitalar, apresentaremos uma proposta de atuação para psicólogos que atuam ou pretendem atuar na área da obstetrícia, que foi construído por nós, durante o referido estágio curricular, que facilitou para estruturamos a nossa atuação nesta área específica.

É importante ressaltar que a demanda para a atuação do psicólogo nesta instituição partiu da diretoria que nos deu total liberdade para atuarmos em todos os setores do hospital. A maternidade e a UTIN, setores pelos quais eu estive como responsável, especificamente não tinham demandas formadas, foi preciso que nós trabalhássemos esta demanda.

$\mathrm{Na}$ maternidade é mais trabalhoso construir a demanda e fazer com que as pessoas percebam que ela existe a partir de cada paciente, principalmente porque a maioria das pacientes atendidas neste setor "não está doente, apenas grávida", e as pessoas não costumam considerar que haja sofrimento no ciclo gravídico-puerperal, afinal este seria um processo natural e instintivo e "a chegada de um bebê só pode trazer alegrias" (Arrais, 2005, p. 30).

Há poucos casos para os quais a equipe de psicologia é solicitada a acompanhar, geralmente para os casos em que os bebês têm alguma má formação, alguma deficiência, ou quando há alguma intercorrência decorrente dos partos, ou ainda em casos de aborto e óbitos, pois o sofrimento das mães fica mais evidente nestas situações. Raramente somos chamadas para intervir de forma a proporcionar a psicoprofilaxia das gestantes e puérperas.

No entanto, ao longo do trabalho desenvolvido nestes setores, foi ficando claro ser de grande relevância a atuação do psicólogo na obstetrícia. Porém, nos deparamos com pouco respaldo teórico para nossa atuação. Observamos uma lacuna teórica existente na literatura disponível na área da psicologia aplicada à obstetrícia, quanto à sistematização de protocolos de atuação do psicólogo neste serviço. Em nossa busca bibliográfica, não encontramos sequer um artigo que abordasse o papel do psicólogo, num centro obstétrico, durante o trabalho de parto e parto, a maioria deles se concentra na atuação no pré-natal ou no aleitamento. Pouco também se fala sobre o atendimento à morte na maternidade. O óbito perinatal aparece basicamente em artigos sobre a atuação nas UTIs Neonataia (UTINs).

Os poucos artigos encontrados como o de Baltazar; Gomes e Cardoso (2010), reforçam a importância de sistematizar rotinas e criar protocolos para uma prática do o psicólogo em UTIN. Portanto, este cenário lacunar, nos motivou a escrever uma proposta de atuação do psicólogo em maternidades e UTINs, na esperança de que a mesma possa inspirar e auxiliar psicólogos interessados nesta área, contribuindo com a evolução da psicologia hospitalar como um todo.

Para justificar a relevância deste artigo, trazemos
Baltazar; Gomes e Cardoso (2010) que afirmam que a construção de rotinas e protocolos em UTINs permite que os próprios psicólogos possam eleger as famílias e bebês que demandam acompanhamento regular, colocando-se disponível a eles para as questões que surgem durante a internação. Assim, defendemos que a inserção do psicólogo em maternidades e UTINs implica na organização de uma proposta de rotina e participação quotidiana nos acontecimentos do serviço, numa proposta que não se restrinja a pareceres psicológicos, mas na abordagem regular das famílias e seus bebês. O psicólogo inserido neste contexto obstétrico, a partir de um enfoque da psicologia hospitalar, irá acolher os pais e auxiliálos na vinculação entre si e com o bebê internado (Terreno, 2012). A escuta destes pais e a compreensão de seus conteúdos internos é fundamental para o entendimento da parentalidade e de como isso está implicado diretamente com as manifestações do bebê.

\section{PROPOSTA DE ATUAÇÃO DO PSICÓlOGO NA OBSTETRÍCIA}

O quadro 1 a seguir apresenta a síntese de todas as atividades que consideramos que o psicólogo hospitalar pode e deve realizar em uma maternidade e na UTIN. Esta proposta de atuação baseou-se na nossa prática construída ao longo de alguns anos de experiência na área da obstetrícia, que foi sistematizada na situação de estágio curricular, no ano de 2011, e que se mostraram viáveis e eficazes para a clientela atendida; bem como na literatura disponível sobre a atuação do psicólogo nesta área específica. A sistematização das atividades que o psicólogo pode e deve realizar em uma maternidade e na UTIN, foi o principal objetivo deste artigo, onde buscar-se-á para cada atividade proposta, o respaldo teórico, dialogando com os estudos e propostas realizadas nesta, nos últimos anos.

\section{DISCUSSÃO DA PROPOSTA DE ATUAÇÃO}

1. Ronda: A atividade de ronda refere-se a uma caminhada junto a gestante pelos corredores do hospital, entrada em enfermarias, UTIN e sala de parto (Camacho, 2006). Nesse momento o psicólogo pode utilizar-se da escuta terapêutica e de técnicas para controle da ansiedade e dor.

Com a ronda o psicólogo hospitalar possibilita às gestantes, puérperas e pais de UTIN, a expressão de uma demanda, ele reconhece a possibilidade de haver um sofrimento, mesmo que a gravidez tenha sido planejada, aceita e que tudo tenha corrido bem durante a gestação, parto e pós-parto. Buscamos sempre mostrar às gestantes e as puérperas que elas têm o direito de sentirem-se tristes, mesmo ao realizarem o sonho de quase toda mulher "o sonho de ser mãe". Procuramos então fazê-las falar sobre este sofrimento. O que fazemos é desmistificar esta idéia, sinalizar que pode haver sofrimento, as 
Quadro 1

Proposta do protocolo de atuação do psicólogo na maternidade e UTIN

\begin{tabular}{|c|c|c|}
\hline Atividades & Definição/ Objetivos & Operacionalização \\
\hline 1. Ronda & $\begin{array}{l}\text { Esclarecer dúvidas e auxiliar na ambientação do } \\
\text { paciente ao hospital, aos procedimentos que estão } \\
\text { sendo feitos e ao tratamento; } \\
\text { Fornecer orientações sobre a gestação, parto, pós- } \\
\text { parto e UTIN; } \\
\text { Triagem de demandas: identificar possíveis } \\
\text { pacientes para admissão na psicologia; } \\
\text { Desmistificar o mito da "mãe perfeita"; } \\
\text { Realizar uma breve avaliação psicológica do (a) } \\
\text { paciente e breve exame do estado psíquico do (a) } \\
\text { mesmo (a) }\end{array}$ & $\begin{array}{l}\text { Visita realizada aos os apartamentos/ } \\
\text { enfermarias nas quais os (as) pacientes } \\
\text { estão internados (as) bem como em } \\
\text { todos os leitos da UTIN. } \\
\text { É realizada diariamente e visa acolher } \\
\text { o (a) paciente e detectar possíveis } \\
\text { demandas para a psicologia. }\end{array}$ \\
\hline $\begin{array}{l}2 \\
\text { Atendimento } \\
\text { de Apoio } \\
\text { Individual às } \\
\text { gestantes e } \\
\text { puérperas }\end{array}$ & $\begin{array}{l}\text { Proporcionar uma escuta atenta à paciente que } \\
\text { passa por um momento delicado de mudanças } \\
\text { intensas; } \\
\text { Quando necessário desenvolver avaliação } \\
\text { psicológica, por meio de testes específicos. (por } \\
\text { exemplo, nos casos dos transtornos emocionais do } \\
\text { pós-parto); } \\
\text { Realizar os encaminhamentos para outros } \\
\text { profissionais } \\
\text { Resgatar sua auto-estima e autoconceito; } \\
\text { Assegurar a parturientes/puérpera a possibilidade } \\
\text { de manutenção de uma boa qualidade de vida, em } \\
\text { vista das mudanças. }\end{array}$ & $\begin{array}{l}\text { Atividade que proporciona atendimento } \\
\text { individual às parturientes, puérperas } \\
\text { que por algum motivo estejam passando } \\
\text { por alguma dificuldade, devido ao } \\
\text { processo de internação, gestação, parto, } \\
\text { dificuldades com a amamentação, entre } \\
\text { outros. } \\
\text { Verificamos as necessidades das } \\
\text { parturientes e puérperas e trabalhamos } \\
\text { suas dificuldades; }\end{array}$ \\
\hline $\begin{array}{l}3 \\
\text { Atendimento } \\
\text { de Familiares } \\
\text { e Acompa- } \\
\text { nhantes }\end{array}$ & $\begin{array}{l}\text { Esclarecer sobre os procedimentos que estarão } \\
\text { sendo feitos no período de internação; } \\
\text { Esclarecer as dúvidas relacionadas aos } \\
\text { procedimentos com o bebê e também com a } \\
\text { paciente; } \\
\text { Orientar quanto às mudanças que ocorrerão na } \\
\text { rotina da família, e a forma como poderão proceder; } \\
\text { Favorecer a socialização e interação da paciente e } \\
\text { da família com equipe; } \\
\text { Oferecer um panorama do que poderá ocorrer a } \\
\text { nível emocional com a parturiente/puérpera e de } \\
\text { que forma agir. }\end{array}$ & $\begin{array}{l}\text { Atendimentos de apoio e orientação à } \\
\text { família das parturientes e puérperas, } \\
\text { que podem ser realizados de } \\
\text { forma individual ou em grupos de } \\
\text { acompanhantes. } \\
\text { Escuta diferencial que visa manter o } \\
\text { equilíbrio e o bem estar da família diante } \\
\text { do momento em que poderão sentir-se } \\
\text { ameaçados, inseguros ou preocupados. } \\
\text { Estimular a participação dos pais e } \\
\text { familiares durante o trabalho de parto e } \\
\text { parto; }\end{array}$ \\
\hline $\begin{array}{l}4 \\
\text { Preparação } \\
\text { para } \quad \text { o } \\
\text { trabalho de } \\
\text { parto e parto }\end{array}$ & $\begin{array}{l}\text { - Preparar psicologicamente a paciente para } \\
\text { enfrentar parto Cesário e normal. } \\
\text { - Incentivar a participação do pai ou do } \\
\text { acompanhante durante todo o processo } \\
\text { - Oferecer atenção integral à parturiente de forma } \\
\text { que ela não se sinta desamparada } \\
\text { - Proporcionar um parto o mais humanizado } \\
\text { possível, segundo as recomendações da OMS. } \\
\text { - Fazer o manejo da dor e da ansiedade }\end{array}$ & $\begin{array}{l}\text { - Assistência à parturiente no pré e } \\
\text { pós-parto. Preparação emocional e } \\
\text { psicológica para o momento do parto. } \\
\text { - Acompanhamento da parturiente } \\
\text { durante o trabalho de parto com } \\
\text { realização de massagens para alívio da } \\
\text { dor e suporte emocional } \\
\text { - Acompanhar a parturiente na sala } \\
\text { de parto de forma a proporcionar } \\
\text { segurança e apoio no momento do } \\
\text { parto seja natural ou Cesário }\end{array}$ \\
\hline
\end{tabular}




\begin{tabular}{|c|c|c|}
\hline $\begin{array}{l}5 \\
\text { Atendimento } \\
\text { aos bebês na } \\
\text { UTIN }\end{array}$ & $\begin{array}{l}\text { - Estimular o vínculo entre os pais e o bebê; } \\
\text { - Estimulação sensorial global aos bebês especiais. }\end{array}$ & $\begin{array}{l}\text { - Favorecer para a humanização do } \\
\text { atendimento aos bebês na UTIN }\end{array}$ \\
\hline $\begin{array}{l}6 \\
\text { Atendimento } \\
\text { e acompanha } \\
\text { mento das } \\
\text { famílias com } \\
\text { bebês na } \\
\text { UTIN }\end{array}$ & $\begin{array}{l}\text { Proporcionar segurança e conforto aos pais e } \\
\text { familiares dos bebês, de modo que cada um receba } \\
\text { acompanhamento e acolhimento específico, diante } \\
\text { de cada caso; } \\
\text { Estabelecer um vínculo maior dos pais com o } \\
\text { hospital e com a equipe, para que então se sintam } \\
\text { mais familiarizados e, portanto mais tranqüilos } \\
\text { durante o período de internação do bebê; } \\
\text { Promover ambientação a UTIN orientando quanto } \\
\text { às rotinas do setor; } \\
\text { Evitar com que esta vivência seja traumática para } \\
\text { os familiares minimizando traumas futuros; } \\
\text { Possibilitar aos familiares expressar suas } \\
\text { dificuldades e sentimento em relação a esta } \\
\text { situação; } \\
\text { Identificar possíveis necessidades de atendimentos } \\
\text { individuais sistemáticos. }\end{array}$ & $\begin{array}{l}\text { Acompanhar os pais ou parentes do } \\
\text { bebê à visita a UTIN e/ou realização } \\
\text { de atendimentos aos familiares } \\
\text { proporcionando um suporte emocional } \\
\text { e favorecendo para que a visita possa } \\
\text { ser vivenciada da melhor forma possível } \\
\text { tanto para os visitantes quanto para o } \\
\text { bebê } \\
\text { Estimular o contato físico entre pais e } \\
\text { bebê } \\
\text { Estimular a comunicação pais bebês, } \\
\text { especialmente o mamanhêz; }\end{array}$ \\
\hline $\begin{array}{l}\text { 7. Pré-natal } \\
\text { psicológico }\end{array}$ & $\begin{array}{l}\text { Trata-se de um novo conceito em atendimento } \\
\text { perinatal, voltado para uma maior humanização } \\
\text { do processo gestacional e do parto e de construção } \\
\text { da parentalidade. O programa visa à integração da } \\
\text { gestante e da família a todo o processo gravídico- } \\
\text { puerperal, através de encontros temáticos } \\
\text { com ênfase na preparação psicológica para a } \\
\text { maternidade e paternidade. } \\
\text { Prevenir a depressão pós-parto. } \\
\text { Desmistificar o papel da psicologia durante o ciclo } \\
\text { gravídico-puerperal } \\
\text { Prevenção de problemas emocionais } \\
\text { O apoio psicológico ao casal grávido para } \\
\text { construção da parentalidade }\end{array}$ & $\begin{array}{l}\text { Atendimento em grupo semanal, aberto. } \\
\text { Oferecer uma escuta qualificada e } \\
\text { diferenciada sobre processo da gravidez, } \\
\text { fornecendo assim um espaço onde a } \\
\text { mãe\pai possa expressar seus medos e } \\
\text { suas ansiedades, } \\
\text { Favorecer a de troca de experiências, } \\
\text { descobertas e informações, com extensão } \\
\text { à família, em especial ao cônjuge e } \\
\text { as avós, visando à participação na } \\
\text { gestação/puerpério e compartilhamento } \\
\text { da parentalidade. } \\
\text { Orientá-las procurar ajuda caso } \\
\text { identifiquem uma mudança patológica. }\end{array}$ \\
\hline $\begin{array}{l}8 \\
\text { Atendimento } \\
\text { psicológico } \\
\text { de apoio a } \\
\text { grupos tais } \\
\text { como: pais } \\
\text { de UTIN; } \\
\text { pais de bebês } \\
\text { de } 0 \text { a } 1 \\
\text { ano; casais } \\
\text { grávido s, } \\
\text { puérperas em } \\
\text { sofrimento } \\
\text { psíquico. }\end{array}$ & $\begin{array}{l}\text { Visa atender grupos homogêneos de pessoas para } \\
\text { trabalhar as problemáticas vividas por cada grupo. }\end{array}$ & $\begin{array}{l}\text { Proporcionar apoio e orientação } \\
\text { relacionados à experiência vivenciada } \\
\text { pelo grupo e favorecer a troca de } \\
\text { experiência entre os participantes } \\
\text { de forma que eles possam se ajudar } \\
\text { mutuamente. } \\
\text { Preparar casais grávidos para o parto } \\
\text { e pós-parto minimizando as dúvidas e } \\
\text { ansiedades provocadas pela gestação e } \\
\text { nascimento do bebê; } \\
\text { Diminuir a sensação de fracasso e } \\
\text { impotência dos pais de UTIN; } \\
\text { Dar suporte emocional aos pais } \\
\text { que vivenciam as dificuldades da } \\
\text { maternidade e paternidade } \\
\text { Prevenir a depressão-pós-parto. }\end{array}$ \\
\hline
\end{tabular}




\begin{tabular}{|c|c|c|}
\hline $\begin{array}{l}9 \\
\text { Atendimento } \\
\text { Psicológico } \\
\text { em domicílio }\end{array}$ & $\begin{array}{l}\text { Assegurar que as gestantes e pais se sintam mais } \\
\text { seguros e amparados. } \\
\text { Favorecer a elaboração do luto em casos de óbitos } \\
\text { de recém-nascidos e aborto. }\end{array}$ & $\begin{array}{l}\text { Visita a gestantes e puérperas em } \\
\text { situações que foi identificado a } \\
\text { necessidade de estender o atendimento }\end{array}$ \\
\hline $\begin{array}{l}10 . \\
\text { Interconsulta }\end{array}$ & $\begin{array}{l}\text { Elaborar e fornecer parecer psicológico sobre as } \\
\text { pacientes; } \\
\text { Possibilitar a socialização e a interação entre } \\
\text { paciente e equipe, essenciais nesse momento; } \\
\text { Esclarecimentos sobre o estado geral da paciente. }\end{array}$ & $\begin{array}{l}\text { Conhecimento dos casos e dos } \\
\text { diagnósticos específicos; } \\
\text { Troca de informações sobre as condições } \\
\text { do paciente; }\end{array}$ \\
\hline $\begin{array}{l}11 . \\
\text { Atendimento } \\
\text { ao óbito } \\
\text { perinatal }\end{array}$ & $\begin{array}{l}\text { Favorecer a elaboração do luto; prevenir traumas } \\
\text { obstétricos futuros e a instalação do luto patológico. }\end{array}$ & $\begin{array}{l}\text { Promover a despedida do bebê } \\
\text { Garantir às famílias um espaço de } \\
\text { expressão da dor da perda } \\
\text { Trabalhar o desligamento do bebê } \\
\text { Incentivar que a mãe se despeça do filho } \\
\text { morto que carrega em seu ventre } \\
\text { Sugerir que lhe dê um nome, caso não } \\
\text { tenha feito. } \\
\text { Facilitar a expressão das emoções } \\
\text { positivas em relação ao filho; } \\
\text { Assegurar que se trata do seu filho e que } \\
\text { ele sempre fará parte da sua história; } \\
\text { Desculpabilizar a mãe, mesmo em casos } \\
\text { de negligência materna; } \\
\text { Respeitar o tempo de elaboração do } \\
\text { luto para indicar a indução do parto ou } \\
\text { incentivar a espera pelo parto espontâneo } \\
\text { Permitir que os pais vejam e toquem (se } \\
\text { quiserem) o filho morto; } \\
\text { Sugerir que organizem o funeral } \\
\text { (fetos>500 grs); } \\
\text { Recolham lembranças possíveis; } \\
\text { Facilitar o contato com a difícil realidade } \\
\text { e com o espaço de expressão das } \\
\text { emoções; } \\
\text { Não poupar a mãe em detrimento da } \\
\text { expressão dos sentimentos; } \\
\text { Cuidar também do pai; } \\
\text { Marcar atendimento ambulatorial } \\
\text { para rastreamento de transtornos } \\
\text { psicopatológicos. }\end{array}$ \\
\hline
\end{tabular}

fazendo sentir menos a sensação de estranhamento e inadequação, e abrimos então o espaço para a escuta deste sofrimento. Se a mulher ousa expressar qualquer sentimento negativo, tanto com a gestação quanto com a chegada do bebê, logo se diz que ela está "rejeitando o filho". Esse tipo associação, que é muito recorrente, é superficial, de cunho excludente e pejorativo. Essas mulheres acabam se sentido uma "aberração da natureza" favorecendo ainda mais para o aumento do sofrimento (Arrais, 2005).

Desta forma, fica mais fácil que as pacientes e seus acompanhantes falem de suas dificuldades e de seus sofrimentos e de entender como as gestantes ou puérperas tem lidado com a gestação, com a chegada do parto e do bebê, bem como com a internação do bebê. De acordo com esta primeira conversa, temos uma visão panorâmica da pessoa de cada pessoa atendida nos setores em questão e podemos fazer uma triagem das gestantes e/ou puérperas que merecem uma maior atenção da psicologia, identificando as que precisam de um atendimento individual e indicando para os atendimentos de grupo.

2. Atendimento de Apoio Individual às gestantes e puérperas: Os atendimentos individuais são realizados em uma perspectiva breve, durante o período em que as gestantes e puérperas permanecerem internados 
(as), podendo os atendimentos ser realizados nos próprios quartos onde se encontram hospitalizados ou nos corredores do hospital. Em alguns casos fazemos os atendimentos na sala da psicologia. Muito embora, consideramos que o setting não exija necessariamente uma sala específica para $o$ atendimento, pois o psicólogo hospitalar deve estar onde os acontecimentos estão, deve circular pelo hospital e atender o paciente em seu quarto ou andar (Simonetti, 2004).

O trabalho do psicólogo hospitalar na maternidade durante o período do puerpério se dá num momento particular em que a questão da filiação está emergente. As mulheres estão às vezes afetadas pelo baby blues, manifestando intensa disposição para se expressar e falar sobre a nova experiência, colocar em palavras o sentimento que emerge com a chegada do novo bebê. Uma intervenção psicológica neste período na maternidade visa prevenir a saúde mental e física da mãe e do bebê, com o objetivo de estimular uma ligação mais saudável entre ambos (AngeramiCamon, 2000). Diante disso, o psicólogo hospitalar na maternidade deve favorecer a psicoprofilaxia do ciclo gravídico-puerperal (Wendland, 2012a; Cabral; Martins \& Arrais, 2012).

Oferecemos este atendimento às gestantes e puérperas que apresentam um sofrimento com a atual vivência, pois como dito anteriormente, a chegada de um bebê pode suscitar sofrimento em vários aspectos tais como: no relacionamento social, na identidade, o medo do parto, a insegurança no papel de mãe, a realização de um parto muito diferente do idealizado, o confronto do bebê real com o imaginário, dentre outros. Atendemos individualmente também àquelas gestantes e puérperas que perderam seus bebês ou durantes a gestação ou após o parto.

3. Atendimento de Familiares e Acompanhantes: Realizamos atendimentos aos familiares e acompanhantes por considerarmos que a família sofre com o impacto da internação e hospitalização da gestante, parturiente ou puérpera. Este sofrimento pode estar relacionado com o impacto da notícia de uma gestação e/ou com o nascimento de um novo ser na família, tanto no que diz respeito ao parto quanto a chegado do bebê. Eles, assim como os pacientes, têm temores, receios, dúvidas, inseguranças, ansiedade, fantasias que causam seus sofrimentos, necessitando de apoio tanto no momento da gestação quanto do pós-parto para superarem essas dificuldades. Os acompanhantes e familiares de gestante e puérperas, também precisarão delimitar um novo espaço para o bebê e pensar sobre os papéis de cada um, cada membro deverá se recolocar com a chegada de um novo membro (Szjer, 1999). O psicólogo hospitalar deverá ajudar neste processo de delimitação do espaço e papéis, ajudar os pais, avós e filhos mais velhos a se adaptarem com a novidade de um novo membro na família favorecendo para um funcionamento saudável da mesma.

Quando há alguma intercorrência na gestação, parto ou pós-parto, que colocam em risco a saúde ou a vida tanto da mãe quanto do bebê, a família também irá precisar de suporte emocional e orientações de nossa parte, pois poderão surgir dúvidas, preocupações quanto à saúde da mãe e do bebê, bem como sentimentos de culpa que devem ser trabalhados. Mesmo que tudo esteja ocorrendo bem, durante o parto a família pode se mostrar angustiada e precisando de um apoio e falar dos medos que surgem neste momento.

4. Preparação para trabalho de parto e parto: A presença do psicólogo durante o trabalho de parto e o parto pode trazer benefícios a parturiente por vários motivos que serão listados aqui. Sabemos que a sensibilidade da dor está ligada a emoção, a coragem, ao medo (Szejer, 1999) e o psicólogo deverá lidar com estas emoções da parturiente durante o trabalho de parto e o parto de forma que facilite este processo. Há várias questões ambientas que podem interferir no trabalho de parto, tanto para atrapalhar a evolução quanto para favorecer a evolução do trabalho de parto, o psicólogo irá mediar estes aspectos, principalmente no que se refere à relação médica e paciente, familiar e parturiente, quando estas estão atrapalhando. O que não significa questionar os procedimentos médicos, mas poderá trabalhar junto com o mesmo informando ao médico o estado emocional da parturiente. $\mathrm{O}$ mais importante é fazê-la tomar o lugar de sujeito, ou seja, fazer com que seja ativa no processo de nascimento de seu filho, incentivá-la a questionar os procedimentos para entender o que se passa com ela. O psicólogo poderá utilizar técnicas de relaxamento e visualização tanto durante o trabalho de parto, quanto durante a espera para a cesárea para aliviar a dor e controlar a ansiedade.

Além disto, a Política Nacional de Humanização (Brasil, 2007) fala da importância da mulher ter um acompanhante no momento do parto, sendo este um direito seu. Defende que o parto envolve o fisiológico, social, cultural, afetivo da mulher e da comunidade, logo não há motivo para que a mulher permaneça sem acompanhante neste momento devemos incentivar principalmente, a participação do pai do bebê, se esta for da vontade da parturiente. Esta participação é benéfica tanto para a parturiente, quanto para o pai e para o bebê, afirmam estudos como os de Carvalho (2003) e Perdomini e Bonilha (2011). A mulher se sente mais amparada quando seu companheiro está presente, ele poderá mencionar palavras de incentivo. Para este, a sua presença pode estar carregada se sentido positivo o que favorece para que ele não se sinta excluído de um momento tão importante de sua vida que a chegada de seu filho. Ele pode se sentir deslocado, ou o sofrimento de sua companheira pode lhe causar grande desconforto, neste caso, a atuação do psicólogo hospitalar será apoiar este pai. A presença 
do pai no momento do parto é de grande importância também para a construção do vínculo entre ele e o bebê. O bebê já conhece a voz de seu pai que foi ouvida durante toda a gestação, sendo para o bebê um conforto ouvir esta voz durante o seu nascimento.

De acordo com Fighera e Viero (2005), a ansiedade provocada pela possibilidade de uma intervenção cirúrgica pode afetar o paciente se este sentimento não for expresso e conscientizado. Os momentos que antecedem a cirurgia são vivenciados pelo (a) paciente de uma forma dramática e assustadora. O medo do desconhecido é a principal causa da insegurança e da ansiedade do paciente pré-cirúrgico. Ele teme a morte, a anestesia, o procedimento em si, a recuperação (Fighera \& Viero, 2005). Segundo Szejer (1999), as parturientes submetidas à cesárea tendem a vivenciar a mesma apenas como uma cirurgia, diminuindo a importância deste momento. Diante dessas características quanto à cesárea, consideramos de grande importância à assistência do psicólogo para a preparação para a cesárea, bem como durante a mesma, ajudando-as a lidar com os medos da cirurgia, podendo assim vivencia um momento único em suas vidas, o no nascimento de seus filhos.

5. Atendimento aos bebês na UTIN: Vários estudos têm mostrado a importância tanto da vida intra-uterina quanto dos primeiros dias de vida do recém-nascido no desenvolvimento psiconeuromotor do mesmo (Corrêa, 2002, 2102, Cunha, 2102). As rotinas das UTIN tradicionais impedem, de certa forma, que o bebê receba os cuidados que o bebê a termo e saudável tem, determinando superestimulação sensorial, dor, estresse e principalmente alteração dos ritmos comportamentais: estados de sonolência interrompidos, choro não consolado, posição supina, manuseio rotineiro e excessivo, ruído ambiental inadequado, pouca oportunidade de sucção e absoluta falta de interação com o olhar, do toque contingente e da linguagem articulada que nomeia o mundo. Esta vivência poderá influenciar nos desenvolvimento do bebê. Porém, por meio de mudanças nos cuidados na UTIN, pode ser possível a obtenção de melhorias de diversos aspectos do desenvolvimento do bebê internado (Cunha, 2002; Silva, 2002, Cunha 2012).

O principal instrumento que deve ser utilizado para minimizar o impacto negativo da internação são as pistas ou os sinais do bebê, reconhecer estas pistas e sinais, tornando-o um parceiro competente na interação, sendo papel do psicólogo ajudar a equipe a reconhecer estas pistas (Silva, 2002, Cunha 2012). É importante lembrar que mesmo sendo bebê, este deve ser considerado como sujeito dotado e emoções, que sente dor e possui sua própria individualidade que deve ser respeitada. Como psicólogos, devemos ajudar a equipe e a família na busca da segurança psíquica do bebê, minimizando ao máximo este sofrimento (Baltazar; Gomes \& Cardoso, 2010). Os bebês são capazes de manifestar prazer, dor, de buscar contato e de fugir do contato quando não suportam o excesso de dor, de estimulação ou de estresse (Brasil, 2002). É preciso estar atento a esta comunicação do bebê.

Fala-se muito sobre os efeitos negativos da hiperestimulação, mas frequentemente esquecemonos que a hipoestimulação também pode ter efeitos negativos sobre o desenvolvimento do bebê. $\mathrm{O}$ importante é que o bebê possa receber atenção em equilíbrio, que levem em consideração suas necessidades psicoativas (Andrade, 2002).

Ao pensarmos no bebê internado na UTIN, devemos lembrar que ele, assim como o bebê que nasceu saudável, precisa ter seu desenvolvimento afetivo preservado e, para que isso ocorra, será preciso da presença dos pais (Brasil, 2002; Baltazar; Gomes \& Cardoso, 2010). Cunha (2002; 2012) mostra que o bebê prematuro, mesmo doente, tem sua capacidade de sedução muito desenvolvida para conquistar o cuidador. Devemos então ajudar os pais a serem conquistados por seu bebê. O psicólogo poderá apresentar o bebê aos pais, mostrar a eles as competências já existentes no seu bebê tais como se virar na direção de suas vozes; mostrar a diferença nos valores de saturação e oxigênio na presença deles, a sensibilidade ao toque.

É importante observar ainda a mudança do ambiente intra-uterino para o ambiente fora do útero e o impacto dessa mudança no bebê. Ainda no útero, Andrade (2002) destaca que ele já realiza atividades e brincadeiras, tais como: tocar na placenta, se agarrar no cordão umbilical, empurrar a parede amniótica com os pés, leva a mãe à boca, dentre outras. Sta mesma autora também aponta para um interesse do bebê em tocar os limites da incubadora com os pés, mãos e cabeça como uma forma de sentir-se seguro, bem como o interesse em segurar objetos (a sonda, por exemplo). Desta forma, pode-se colocar um tecido sobre o corpo do bebê (quando possível) e possibilitar-lhe um ponto de apoio, segurar algo. Estes recursos podem significar para ele uma continuidade importante para a organização da vida psíquica no ser humano.

Como apresentado no quadro acima, a atuação do psicólogo na UTIN deverá favorecer a humanização do atendimento ao bebê internado, isto significa intervir tanto no ambiente físico quanto no ambiente humano que cerca o bebê (Baltazar; Gomes \& Cardoso, 2010). O Manual de Atenção Humanizada ao recém-nascido de baixo peso (Brasil, 2002) dos apresenta algumas sugestões que podem ser utilizadas pelos psicólogos para favorecer a humanização na UTIN, tais como: conversar com o bebê, explicar-lhe por que está na UTI; oferecer conforto através do toque; friccionar as mãos para aquecê-las antes de tocar o bebê; chamálo pelo nome, orientando a equipe a fazer o mesmo; orientar a equipe a também conversar com o bebê e avisar sempre que for fazer algum procedimento. 
Lembrando de estar atento para os sinais de estresse do bebê.

6. Atendimento e acompanhamento das famílias com bebês na UTIN: Na UTIN fundamentamos a nossa atuação em uma pesquisa que abordou o sofrimento das mães na UTIN, na qual as mães desta instituição foram as participantes entrevistadas. Nesta pesquisa pudemos perceber quais eram os principais motivos de sofrimento nos permitindo atuar junto às mesmas, tais como: se deparar com o bebê real, que é diferente do bebê imaginário; o contato com um ambiente estranho; o medo da perda do filho; a insegurança de lidar com um "bebê problema"; o sentimento de culpa e fracasso; o relacionamento com outros profissionais; a falta de informação sobre o estado de saúde do filho e tratamento, dentre outros (Mourão, 2006). Consideramos, e temos observado, que os pais e os avós também sofrem com a internação do bebê e também necessitam de apoio.

Além dos sentimentos citados acima, todas as referências sobre maternagem, paternagem e cuidados com o bebê apresentadas pela família, parecem não fazer sentido, pois ele encontra-se internado, sob o cuidado da equipe de saúde. Quando o bebê nasce prematuro, o casal não pôde viver psiquicamente no final da gestação as questões próprias deste período para a preparação da chegada do bebê (Valansi \& Morsch, 2004), desta forma, será preciso então integrar a realidade a vivencia da família. O psicólogo deverá então ajudá-los a fazer esta integração, possibilitandoos falar sobre essa vivencia, a falarem sobre este nascimento e internação, que provavelmente não era esperado, ajudá-los a abrir espaço para o bebê real e fazer o luto do bebê imaginário.

Para isso é de fundamental importância à presença dos pais no ambiente da UTIN, a presença deles neste ambiente é tão importante para o bebê quanto para eles próprios. Segundo Andrade (2002), quando os pais são privados de ver seu bebê logo após o nascimento, eles podem apresentar dificuldades em demonstrar um sentimento caloroso e espontâneo em relação ao bebê. Afinal de contas, quando o bebê nasce prematuro, os pais também se encontram prematuros na aquisição de suas funções de pai e mãe, e o contato com o filho era favorecer para a construção desses papéis. Porém, deverão receber o apoio necessário ao freqüentarem ao UTIN, será preciso criar um ambiente propício à formação e ao fortalecimento dos laços afetivos (Baltazar; Gomes \& Cardoso, 2010).

Procuramos também seguir as sugestões trazidas por Valansi e Morsch (2004) e Morsch e Delamonica (2005). Eles nos apresentam algumas atividades que podem ser realizadas na UTIN junto aos familiares, tais como: colocar-se como referência na equipe, pois há uma grande rotatividade de profissionais; ajudar os pais a olhar este bebê como um outro, para que possam investi-lo como sujeito; ajudar na comunicação pais/bebês, mostrando aos pais as qualidades e capacidades de seus bebês; orientá-los e favorecer na participação dos cuidados com o bebê, para se aproximarem da função de pai e mãe; ajudar a comunicação pais/equipe, entendendo que a equipe é alvo de projeção dos pais.

Estes autores acrescentam ainda que o psicólogo deverá ajudar os irmãos dos bebês de UTIN a lidarem com esta nova situação. A chegada de um bebê saudável já provoca mudanças que podem trazer sofrimento para os filhos mais velhos do casal, a internação do bebê poderá agravar este sofrimento, pois certamente irá levar a uma separação maior com os pais (Morsch. \& Delamonica, 2005). Torna-se difícil também para os pais se dividirem entre os filhos que estão em casa o que se encontra na UTIN. O psicólogo poderá atuar então favorecendo visitas dos irmãos mais velhos, incentivando na participação dessa experiência junto com a família; ajudar na compreensão do que ocorre com o bebê; auxiliar para reforçar seu lugar na família (Valansi \& Morsch, 2004). Lembrando que na intervenção junto aos irmãos, deve-se levar em consideração a idade do irmão orientando de forma que sua estrutura cognitiva permita a compreensão da situação (Morsch. \& Delamonica, 2005).

A principal função desse trabalho com a família na UTIN é proporcionar a psicoprofilaxia ao desenvolvimento das relações desse grupo familiar, além de minimizar o sofrimento daqueles que têm um bebê internado (Brasil, 2002), incluindo seus irmãos.

7. Pré-natal psicológico: O pré-natal psicológico é complementar ao pré-natal tradicional realizado pelo médico, tem caráter psicoterapêutico e oferece apoio emocional, discute soluções para demandas que podem surgir no período gravídico-puerperal, como aquelas relacionadas aos mitos da maternidade, sua idealização, à possibilidade da perda do feto ou bebê, gestação de risco, malformação fetal, medo do parto, da dor, transtornos psicossomáticos, transtornos depressivos e de ansiedade, mudanças de papeis familiares e sociais, alterações na libido, conflito conjugal, ciúme de outros filhos, planejamento familiar, além de sensibilizar quanto à importância do plano de parto e do acompanhante durante o trabalho de parto e parto (Cabral; Martins; Arrais, 2012).

Essa intervenção, também denominada de psicoprofilaxia por Bortoletti (2007), justificase segundo Maldonato (1982) por ser preventivo em vários aspectos: modificações da identidade da gestante; acompanhar a gestação do vínculo paisbebê; trabalhar o desenvolvimento da confiança na própria percepção e na própria sensibilidade; ampliar recursos do casal como agente de prevenção (Wendland, 2012b) com outras pessoas da família; e conscientização dos pais em relação ao atendimento que recebem e à reivindicação de suas necessidades. Além desses aspectos preventivos o grupo pode colaborar e desmistificar alguns temas importantes, como cuidados com amamentação, cuidados com o 
bebê, a maternidade idealizada.

Para participar do pré-natal psicológico, a gestante não precisa, necessariamente, estar atravessando dificuldades emocionais. Basta explicitar o interesse para construir o novo papel materno ou para aprimorar tal função de responsabilidade e complexidade, uma vez que a construção do vínculo mãe-bebê-pai demanda tempo e elaboração (Terreno, 2012).

O pré-natal psicológico objetiva, ainda, proporcionar as gestantes um entrosamento com outras mulheres que comunguem sentimentos e emoções presentes nessa fase de suas vidas, favorecendo o mecanismo de identificação. Os encontros do grupo têm por finalidade acolher e dar voz a elas, informar, orientar e prepará-las para que passem por esse processo da melhor maneira possível. Para tanto, diversos temas são desenvolvidos ao longo da existência do grupo, levando-se em conta as características e necessidades deste homem no ciclo gravídico-puerperal e as mudanças que ocorrem neste período.

8. Atendimento psicológico de apoio a grupos tais como: pais de UTIN; pais de bebês de 0 a 1 ano; gestantes, puérperas em sofrimento psíquico: Assim como Delfino (2004), entendemos que o contexto grupal desenvolve naturalmente um espaço para o movimento da promoção da saúde através de um processo de ensinar-aprender. As ações educativas em saúde mediante atividades grupais com indivíduos em situação de vida comum, podem se constituir num método privilegiado de investigação-intervenção. Os grupos que aqui propomos - pais de UTIN, pais de bebês de 0 a 1 ano, gestantes, puérperas em sofrimento psíquico - são de apoio psicológico, sabemos que todas essas situações podem produzir conflitos, mudanças, sofrimento, enfim, problemáticas comuns a cada grupo, propomos então a união dessas pessoas com a finalidade de discutir, refletir e tentar encontrar solução para essas problemáticas.

Cada grupo, além de ser informativo, ainda abre espaço para expressão de vivências, de fantasias irracionais, ilógicas, de sentimento que podem surgir em todo o processo do ciclo gravídico-puerperal, sobre os quais nunca ou quase nunca se fala fora do contexto terapêutico de grupo. Segundo Maldonado (1982) o que faz mal é o "não-falado", o sufocado, vivido com culpa e vergonha. Como vimos anteriormente, estes dois sentimentos estão muito presentes na gestação e no pós-parto, sendo preciso expressá-los e perceber que outras pessoas também os sentem.

Para que este clima de comunicação e expressão seja possível, o coordenador precisa ter como qualidade básica à capacidade de elaborar o medo de expressão de sentimentos, legitimando a comunicação sem tentar cerceá-la com excesso de informação ou com mensagens apressadas de tranqüilizarão (Maldonado, 1982). Em todos os grupos incentivamos a troca de experiência, pois consideramos que a vivência de uma pessoa pode ajudar a elaborar sua própria vivência.

9. Atendimento Psicológico em domicílio: Em alguns casos o contato é estendido para atendimento domiciliar ou por telefonemas aos pacientes, quando consideramos o caso grave ou numa tentativa de assegurar que as gestantes e pais se sintam mais seguros e amparados. São casos como, por exemplo, óbito de algum bebê da UTIN, em que a equipe da psicologia não estava presente, cujos pais vinham sendo acompanhados por nós, ou quando verificamos a necessidade, ou seja, percebemos que na alta algo não estava bem.

Nos casos de óbito, este contato é feito por nós, na maioria das vezes, com o intuito de favorecer a elaboração do luto, pois, o que se observa, tanto nestes casos quanto em casos de aborto, é que as pessoas que estão em volta negam o sofrimento destes pais.

Os contatos são estendidos também a puérperas que nos procuram, já que no momento da ronda citamos este atendimento domiciliar aos pacientes, pois entendemos que as maiores dificuldades irão aparecer quando elas voltarem para suas casas. Tendo em vista que neste hospital os cuidados do bebê são realizados em grande pela auxiliar de enfermagem, em casa ela deverá assumir estes cuidados (acrescentara diferença do bebê real $\mathrm{x}$ imaginário, o conhecimento do bebê). Não pretendemos com os atendimentos domiciliares seja um acompanhamento contínuo e prolongado, são intervenções pontuais. Caso seja verificada uma necessidade de um acompanhamento prolongado, fazemos o encaminhamento necessário.

10. Interconsulta: Como dito anteriormente, nós realizamos a Ronda com o intuito de abranger todas as mulheres atendidas no hospital, onde iremos abrir espaço para a demanda. Porém, podemos ser solicitados a avaliar e atender um paciente. Trata-se da interconsulta, na qual o psicólogo é chamado a tratar de questões psicológicas que o paciente apresenta no decorrer do atendimento médico.

Segundo Marinho e Caballo (2001) o profissional que faz o pedido da interconsulta atendia o paciente antes e continuará atendendo após a interconsulta. $\mathrm{O}$ interconsultor é sempre um especialista de outra área, chamado a esclarecer, diagnosticar ou dar solução a uma problemática de saúde, que o paciente tenha e que fuja da competência do profissional ou da equipe responsável. O essencial da ação do psicólogo é ser capaz de fazer uma rápida análise da situação para identificar a origem do problema. Procurar envolver os outros profissionais da saúde, identificar ações que possam surtir efeitos imediatos como, incentivar o médico a esclarecer o problema do paciente, solicitar o serviço social quando necessário (Marinho \& Cabalho, 2001). Consideramos esta uma atividade que pode ser realizada na maternidade, bem como na UTIN, principalmente para identificar nas gestantes e puérperas uma depressão, ou algum outro transtorno próprio destes momentos. 
11. Atendimento ao óbito perinatal: É nosso papel como psicólogos hospitalares favorecer para que este luto possa ser elaborado. Primeiramente abrindo espaço para que se fale deste filho que as pessoas tendem a desconsiderar; verificar se há um desejo dos pais de realizarem algum procedimento ritualístico e favorecer para que o mesmo possa ser realizado; proporcionar algum teste de realidade, verificando se os pais viram o corpo do bebê no caso de recémnascidos, ou sabem o que seria feito do feto em caso de aborto; explicando-lhes que este luto pode levar tempo ao contrário do que as pessoas costumam considerar. Estes procedimentos devem levar em consideração as diferenças entre os pais, não devendo ser algo padronizado.

Iaconelli (2007), Arrais; Muza; Sousa e Iaconelli (2012), Chatelard e Freire (2012) apontam para uma falta de reconhecimento social da dor dos pais na morte de um feto ou recém-nascido. As pessoas não entendem esta perda como a perda de um filho cujos pais vinham investindo psiquicamente. Usam frases como "você é jovem, poderá ter outros filhos", como se outro pudesse substituir o lugar do filho que perderam. Desta forma, as condições mínimas para a elaboração do luto nestes casos, tendem a ser negligenciadas.

Carvalho e Meyer (2007) confirmam que um dos principais papéis da psicologia diante de intercorrências como o luto perinatal é desafiar a mentalidade da morte como tema interdito, buscando identificar as vulnerabilidades e alto risco dos pais que perderam seus filhos. Cabe a psicologia ajudar com que os pais e familiares se apropriem da situação que estão vivendo, para posteriormente conseguirem falar e aos poucos assimilar, e bem posteriormente aceitar. Arrais; Muza; Sousa e Iaconelli (2012), trazem que os rituais fúnebres ajudam no processo de luto, pois a recuperação é centrada na aceitação, e o velório permite que as pessoas se despeçam e que o enlutado seja considerado como tal. Abordagens terapêuticas que possibilitam ajudar os pais no processo de perda do filho, bem como torná-la mais real consistem em permitir que os pais visitem o recém-nascido, toquem-no, caso queiram, e que recolham lembranças possíveis (Bartilotti, 2007). Essas são estratégias que favorecem a saúde psíquica de muitos casais e de seus futuros bebês, que é objetivo primordial da psicologia hospitalar.

De acordo com Carvalho (2010) e Chatelard e Freire (2012), o processo de luto envolve um trabalho pessoal de adaptação à perda. É através do luto que aprendemos a lidar com a morte, com as perdas e com o sofrimento causado por estas. Este período de adaptação caracterizado pela dor e sofrimento deve ser encarado como normal e necessário, sendo fundamental sua elaboração, para que a perda seja enfrentada de forma saudável, não evoluindo de maneira patológica (Bortoletti, 2007). Para Arrais;
Muza; Souza e Iaconelli (2012), o papel do psicólogo nesse contexto é então o de "prevenir" possíveis psicopatologias relacionadas à vida ou morte do bebê, além do esclarecimento e atenção às fantasias dos pacientes. A elaboração do luto do bebê precisa ocorrer de forma a devolver a saúde mental e a reestruturação psíquica a todos os que sofreram com essa perda.

Para finalizar, corroboramos os desafios apontados por Baltazar; Gomes e Cardoso (2010), que também nortearam o nosso quotidiano como psicólogos em maternidades e UTINs e que certamente serão encontrados pelos psicólogos interessados nesta área de atuação:

- Sensibilizar a equipe para a dimensão subjetiva que cada mãe, família e bebê traz consigo, para além de sua dimensão física e história clínica.

- Facilitar a comunicação efetiva da equipe obstétrica com os pais, principalmente quando estes não correspondem às exigências que lhes são feitas, ou quando estão diante de más formações do bebê, prognósticos fechados e óbitos perinatais.

- Dividir com a equipe as expectativas e angústias produzidas pelo trabalho com gestantes de alto risco, trabalhos de parto complicados e os bebês prematuros.

- Propiciar um espaço para que pai, mãe e bebê tenham uma vida afetiva em comum, participando dos cuidados dispensados ao seu bebê.

\section{CONSIDERAÇÕES FINAIS}

Quando tratamos do serviço psicológico no contexto hospitalar, primeiro é percebida a diferença de setting em relação à atuação clássica do profissional de psicologia. $\mathrm{O}$ atendimento com as pacientes é feito em geral junto ao leito, contudo a questão de setting como Simonetti (2004, p, 156) aponta em seu livro sobre a psicologia hospitalar, que "nesse ambiente em geral a capacidade de escuta é mais importante do que um setting pré-determinado, pois a sua construção é dada em grande parte de forma psicológica".

Em consonância com esta premissa, quando considerando a pratica no Hospital Planalto, que foi o campo de experimentação do estágio, esse quesito se expressa, o atendimento por vezes é conduzido além do leito, nos corredores, na sala de espera, de parto, junto à equipe médica, sendo em alguns casos feita a intervenção com o acompanhante das pacientes.O que fizemos acima de tudo como psicólogos hospitalares, foi abrirmos espaço para a subjetividade das gestantes, parturientes e puérperas, seus familiares e seus bebês; sendo este um trabalho específico do psicólogo, pois, além dele, nenhum outro profissional da área da saúde foi treinado a fazer (Simonetti, 2004).

Não obstante esta especificidade do profissional da psicologia, o atendimento deve sempre ser realizado dentro de um parâmetro interdisciplinar, pois este e continente e inspira maior segurança e tem maior 
probabilidade de êxito nos seus resultados, pois há uma gama de conhecimentos técnicos e científicos que se complementam entre si visando um objetivo comum. Assim, o psicólogo hospitalar deve procurar se inserir na equipe fazendo parte da mesma somando com o seu saber, procurando fazer um trabalho interdisciplinar (Moretto, 1999).

Percebemos que não existia um trabalho em equipe estabelecido na maternidade e UTIN do Hospital Planalto, cada profissional faz o que lhe cabe sem que os casos sejam discutidos entre os profissionais da saúde. O padrão é a comunicação apenas pelo o prontuário, o médico deixa as prescrições as quais são executadas pelos enfermeiros e auxiliares. Os outros membros, fisioterapeutas, nutricionistas, fonoaudiólogos e psicólogos, também deixam seus registros nos prontuários sem uma discussão ou comunicação verbal com os outros membros, o que muitas vezes, dificultou o nosso trabalho e pode ser um verdadeiro entrave a atuação do psicólogo. Mas, reconhecemos, assim como Baltazar; Gomes e Cardoso (2010), que muitos encaminhamentos feitos pela equipe traduzem suas dificuldades em lidar com as repercussões emocionais da internação em neonatologia, o que demanda trabalho interdisciplinar justificando a presença de psicólogos nas equipes.

Cabe ressaltar ainda que, de modo geral, a prática dentro do Hospital Planalto, reflete os trabalhos feitos por outros pesquisadores e profissionais da psicologia, citados ao longo deste artigo, contudo devemos sempre nos atentar na diversidade de realidades que se apresentam no ambiente hospitalar, muitas vezes nossas ações são restringidas pela instituição, em outros momentos facilitados em comparação a outros contextos. A experiência certamente mostra que existem alguns fatores que são chave na atuação do psicólogo da saúde, determinação, uma postura ativa, disponibilidade, flexibilidade e criatividade, pois muitas vezes é necessário lançar mão de instrumentos e técnicas ou mesmo de settings que não são tradicionais, contudo o suporte pode ser feito, e este atendimento faz diferença no trabalho na obstetrícia.

Consideramos que o papel e tarefas do psicólogo hospitalar ainda encontram-se em construção. Destacamos no nosso artigo, a proposta de algumas "novidades" ainda pouco realizadas na prática desta área como o pré-natal psicológico e o atendimento ao óbito perinatal. Assim, esperamos que o presente trabalho possa inspirar psicólogos e que esta proposta de atuação possa acrescentar na prática dos psicólogos hospitalares de maternidades e UTIN.

\section{REFERÊNCIAS BIBLIOGRÁFICAS}

Andrade, M A. G. (2002). Considerações Sobre o Desenvolvimento Psicoafetivo do Bebê Pré-termo. In: CORREIA FILHO, L.; et al (orgs). Novos Olhares Sobre a Gestação e a Criança até os 3 anos: Saúde Perinatal, Educação e Desenvolvimento do Bebê. (1 ${ }^{\mathrm{a}}$ ed, pp. 438-457). Brasília: L.G.E.
Angerami-Camon, V. A. (2000). Psicologia da Saúde - Um Novo Significado para a Prática Clínica. São Paulo: Pioneira Thomson Learning.

Arrais, A. R (2005). As Configurações Subjetivas da Depressão Pós-Parto: Para Além da Padronização Patologizante. 2005. 158 f. Dissertação (Doutorado em Psicologia) - Universidade de Brasília, DF.

Arrais, A.R; Muza, J. C.; Sousa, E. M. \& Iaconelli, V. (2012). Quando a morte visita a maternidade: papel do Psicólogo Hospitalar no atendimento ao luto perinatal. Revista Psicologia Teoria e Prática. No prelo.

Baltazar, D. V. S.; Gomes, R. F. S.; Cardoso, T. B. D. (2010). Atuação do psicólogo em unidade neonatal: rotinas e protocolos para uma prática humanizada1. Rev. SBPH, 13(1): 02-18.

Brasil (2002). Ministério da Saúde. Secretaria de Políticas de Saúde. Área de Saúde da Criança. Atenção humanizada ao recémnascido de baixo peso: método mãe-canguru: manual do curso. Brasília: Ministério da Saúde.

Brasil. (2007). Ministério Da Saúde. Humaniza SUS: Visita aberta e direito a acompanhante. Brasília. Ministério da Saúde.

Bortoletti, F. F. (2007). Psicoprofilaxia no Ciclo Gravídico Puerperal. In: Bortoletti, F. F. et al., Psicologia na prática obstétrica: abordagem interdisciplinar. Barueri: Manole, p. 37-46.

Cabral, D. S. R., Martins, M. H. F., \& Arrais, A.R. (2012) Grupo de pré-natal psicológico: avaliação de programa de intervenção junto a gestantes. Encontro: Revista de Psicologia. No prelo.

Camacho, R. S. et al. (2006) Transtornos psiquiátricos na gestação e no puerpério: classificação, diagnóstico e tratamento. Rev. Psiquiatr. Clín., 33 (2), 92-102.

Carvalho, M. L. M. (2003). Participação dos pais no nascimento em maternidade pública: dificuldades institucionais e motivações dos casais. Cad. Saúde Pública, 19 (2), 389-398.

Carvalho, C. et al. (2010). Luto por morte perinatal emoções em saúde contributos. Corrente Dinâmica. Pág $170<$ http: //www. correntedinamica.com/pubfatout.pdf $>$ Acesso 1 Junho 2012.

Carvalho, F. T. \& Meyer, L. (2007). Perda gestacional tardia: aspectos a serem enfrentados por

mulheres e conduta profissional frente a essas situações. Boletim de Psicologia, 57 (126), 33-48.

Chatelard, D. S \& Freire, T. C. (2012). Natimorto Invisível In: Wendland, J.; Correia Filho, L.; Lucena, L. H. \& Barr, M. ' (orgs). Primeira infância: idéias e intervenções oportunas. p. 108-113. Brasília: Editora Senado.

Correia Filho, L.; et al (orgs). (2002). Novos Olhares Sobre a Gestação e a Criança até os 3 anos: Saúde Perinatal, Educação e Desenvolvimento do Bebê. Brasília: L.G.E.

Cunha, I. Neurobiologia do Vínculo (2002). In: Correia Filho, L.; et al (orgs). Novos Olhares Sobre a Gestação e a Criança até os 3 anos: Saúde Perinatal, Educação e Desenvolvimento do Bebê. p. 353-387 Brasília: L.G.E.

Cunha, I. (2012). A comunicação mãe-bebê: o crescimento do cérebro em desenvolvimento e a gênese dos processos mentais no início da vida In: Wendland, J.; Correia Filho, L.; Lucena, L. H. \& Barr, M. ${ }^{\text {a }}$ (orgs). Primeira infância: idéias e intervenções oportunas. p. 67-71 Brasília: Editora Senado.

Delfino, M. R. R.(2004). O processo de cuidar participante com grupo de gestantes: repercussão na saúde integral individual coletiva. Ciência e Saúde Coletiva, 9 (4), 33-38.

Duarte, T. (2010). Luto por perda fetal. emoções em saúde contributos. Corrente Dinâmica. Pág 162. < http: //www. correntedinamica.com/pubfatout.pdf $>>$ Acesso em: 1 Junho 2012.

Fighera, J.; Viero, E. V. (2005). Vivências do paciente com relação ao procedimento cirúrgico: fantasias e sentimentos mais presentes. Rev. SBPH, 8 (2), 51-63.

Iaconelli, V. (2007). Luto Insólito, desmentido e trauma: clínica psicanalítica com mães de bebês. Revista Latino Americana de Psicopatologia Fundamental, 10 (4), 614-623.

Maldonado, M. T. (1982). Maternidade e Paternidade: preparação com técnicas de grupo. Rio de Janeiro, Livraria Atheneu.

Marinho, M. L. \& Cabalho, V. E. (org). (2001). A Prática da 
Psicologia Hospitalar. In: Psicologia Clínica e da Saúde. ( $\left(1^{\text {a }}\right.$ Ed, pp. 263-278). Editora: UEL - Granada: APICSA.

Morsch, D. S. \& Delamonica, J. (2005). Análise das repercussões do Programa de Acolhimento aos Irmãos de Bebês Internados em UTI Neonatal: "Lembraram-se de Mim!". Ciência \& Saúde Coletiva, 10(3), 677-687.

Moretto, M. L. T. (1999). A problemática da inserção do psicólogo na instituição hospitalar. Revista de Psicologia Hospitalar, 9 (2), 19-23

Mourão, M. A. (2006). O Sentido Subjetivo das Mães de UTIN. Monografia (Graduação em Psicologia) - Universidade Católica de Brasília, DF.

Perdomini, F. R. I. \& Bonilha, A. L. L.. (2011). A participação do pai como acompanhante da mulher no parto. Texto \& Contexto - Enfermagem, 20(3), 445-452.

Silva, R. N. M. (2002). Aspectos Comportamentais Pré-termo na UTIN. In: Correia Filho, L.; et al (orgs). Novos Olhares Sobre a Gestação e a Criança até os 3 anos: Saúde Perinatal, Educação e Desenvolvimento do Bebê. ( $1^{\mathrm{a}}$ ed., pp. 407-421). Brasília: L.G.E.

Simonetti, A. (2004). Manual de Psicologia Hospitalar. Casa do Psicólogo, São Paulo.

Szejer, M. (1999). A Escuta psicanalítica de bebês em maternidade. Anais IV Encontro Brasileiro para o Estudo do Psiquismo Pré e Perinatal. ABREP - Associação Brasileira para o Estudo do Psiquismo Pré- e Perinatal: Casa do Psicólogo.

Terreno, S. (2012). Vinculação na primeira infância: a trama das interações familiares. In: Wendland, J.; Correia Filho, L.; Lucena, L. H. \& Barr, M. ${ }^{a}$ (orgs). Primeira infância: idéias e intervenções oportunas. p. 56-66. Brasília: Editora Senado.

Wendland, J (2012a). Prevenção, intervenções e cuidados integrais na gravidez e no pós-parto. In: Wendland, J.; Correia Filho, L.; Lucena, L. H. \& Barr, M. ${ }^{a}$ (orgs). Primeira infância: idéias e intervenções oportunas. p. 25-38. Brasília: Editora Senado.

Wendland, J (2012b). A prevenção em perinatalidade e a primeira infância: o exemplo dos acolhimentos coletivos paisbebês. In: Wendland, J.; Correia Filho, L.; Lucena, L. H. \& Barr, M. ${ }^{a}$ (orgs). Primeira infância: idéias e intervenções oportunas. p. 39-55. Brasília: Editora Senado.

Valansi, L. \& Morsch, D. S. (2004). O Psicólogo como facilitador da Interação Familiar no Ambiente de Cuidados Intensivos Neonatais. Psicologia Ciência e Profissão, 24 (2), 112119 .

Recebido: 23/07/2012

Última revisão: 13/09/2013

Aceite final: 20/09/2013 
Sobre os autores:

Alessandra da Rocha Arrais - Doutora em Psicologia pela Universidade de Brasília; psicóloga clínica; psicóloga Hospitalar Psicóloga Hospitalar da Secretaria de Estado de Saúde do Distrito Federal (SES-DF); Docente do Curso de graduação em Psicologia e do Mestrado em Gerontologia da Universidade Católica de Brasília (UCB) e do Mestrado Profissionalizante em Saúde da Mulher e dos Idoso da FEPECS.

E-mail: arrais@ucdb.br

Mariana Alves Mourão - Graduada em psicologia pela UCB; especialista em Psicologia Hospitalar e da Saúde pela UCB e Psicóloga Hospitalar da Secretaria de Estado de Saúde do Distrito Federal (SES-DF). E-mail: mariana.amourao@gmail.com 